\title{
Birds-Dead and Deadly: Why Numeracy Needs to Address Social Construction
}

Joel Best

University of Delaware, joelbest@udel.edu

\section{Recommended Citation}

Best, Joel. "Birds-Dead and Deadly: Why Numeracy Needs to Address Social Construction." Numeracy 1 , Iss. 1 (2008): Article 6. DOI: http://dx.doi.org/10.5038/1936-4660.1.1.6 


\title{
Birds-Dead and Deadly: Why Numeracy Needs to Address Social Construction
}

\begin{abstract}
Sociologists use the term social construction to refer to the processes by which people assign meaning to their world. This paper argues that numeracy education needs to address social construction. In particular, thinking critically about the statistics the news media report regarding social issues requires understanding the competitive nature of the social problems marketplace, and the social forces that allow questionable numbers to receive widespread public attention. Such critiques must incorporate more than assessing how the numbers were calculated; they must consider the social construction of particular statistics. Two recent examples-claims about the number of birds killed flying into windows, and warnings about the threat of an avian flu pandemic-are presented to illustrate the need to incorporate social construction into numeracy education.
\end{abstract}

\section{Keywords}

social construction, numeracy, bird collisions, avian flu

Creative Commons License

(c) (1) (3)

This work is licensed under a Creative Commons Attribution-Noncommercial 4.0 License 


\section{Introduction}

Although the people promoting numeracy (a.k.a. quantitative literacy, quantitative reasoning, statistical literacy) come from a range of disciplines, they share a sense of disappointment with many students' limited abilities to apply quantitative concepts in practical situations. Today's students spend more years studying mathematics than their counterparts in the past, yet critics argue that innumeracy remains a serious problem, that students have difficulty applying their math training to real-world situations. In response, instruction in numeracy seeks to help students apply their quantitative skills to reading graphs, understanding interest rates on home loans and credit cards, and other practical situations.

I am tangentially involved with - rather than part of - the numeracy movement. My training is in sociology, but I do not teach courses in statistics or research methods, nor do I do much in the way of quantitative analysis. Most of my work concerns the sociology of social problems. That is, I try to understand how and why particular issues come to public attention. Most often, when people are trying to arouse concern about some social problem, they incorporate statistics in their claims. Many of these numbers have serious flaws, and thinking about those flaws brought me into contact with numeracy's advocates.

In 2001, I published a short book, Damned Lies and Statistics: Untangling Numbers from the Media, Politicians, and Activists (Best 2001). I wanted to write a more sociologically sophisticated version of Huff's (1954) classic, How to Lie with Statistics; that is, I viewed my book as a guide to thinking critically about the sorts of figures used to convince people that they ought to worry about social problems. A sequel, More Damned Lies and Statistics: How Numbers Confuse Public Issues followed (Best 2004). As people in the numeracy movement became aware of my books, I began to receive invitations to attend their conferences (and to write this essay). In this paper, I want to summarize the social constructionist approach taken in my books - maintaining my customary focus on statistics used to promote social problems claims - and to suggest what I see as its relevance for those concerned about numeracy. However, my perspective remains that of someone outside the movement, and insiders will have to judge for themselves whether my ideas are useful.

\section{What Sociologists Mean by Social Construction}

The term social construction flourished briefly as a trendy bit of academic lingo during the 1990s. After originating within sociology (Berger and Luckmann 
1966), it spread, first to the other social sciences, and then to the humanities. Soon all manner of intellectuals claimed to be studying the social construction of this or that, although what they meant when they invoked the term varied a great deal (Best 2008). Many in the sciences - and, I presume, mathematics - came to associate the term with postmodernism, or with postures of extreme relativism (e.g., Boghossian 2006). It is important to understand that that is not what sociologists mean by social construction.

When sociologists speak of social construction, they are referring to the process by which people assign meaning to the world. Human beings depend upon language; they must learn their vocabularies from - and use those words to communicate with - other people. This is a social process through which all knowledge is generated. (To be clear, sociologists use the term "social" very broadly, as encompassing all of the ways people interact. Thus, they understand politics, economics, and so on to be forms of social activity.) We cannot reason without resorting to language; thus, all that we know is embedded in social life.

In particular, it is important to appreciate that numbers are social constructions. This makes some people nervous; they prefer to think that "the truth is out there," that science or mathematics merely discover the universe's secrets. I am not interested in such philosophical issues. Sociologists, however, view science and mathematics as having histories, in which individual people add to the edifice of what is known. Those histories are not always straightforward; they feature debates and occasional backtracking, until consensus emerges regarding how much confidence we should have in the knowledge being produced. That intellectual building project — enlarging our body of knowledgeis a form of social construction.

The significance of these rather abstract claims for numeracy can be better understood if we examine how numbers are used to understand social problems. Within our culture, there is a tendency to assume that statistics are factual, that statistical evidence is more than mere opinion. After all, numbers suggest that someone must have counted something. But that's the point: statistics do not exist in nature; they are always produced by people. People have to decide whether to count, what to count, how to go about counting, and how to summarize the results of that counting process. (Here, and throughout this paper, I use "counting" in a general, non-technical sense; I mean it to encompass the full range of quantitative maneuvers. All numbers-tallies, but also rates, inferential statistics, and all other figures - are the results of people's activities.) This process - this social process - is what sociologists mean when they say that statistics are socially constructed.

It is important to be clear about this: when sociologists say that a statistic is socially constructed, they are not claiming that the number is false, bogus, generated through bad quantitative practices, or otherwise flawed. They do not 
draw a distinction between socially constructed numbers and good numbers. Rather, they view all numbers as socially constructed; every number is a product of people's choices. To be sure, some of those choices may be wiser and more defensible, so that we can have great confidence in the accuracy of the figures. But other numbers may be the results of flawed methods of counting, and we ought to treat those figures with considerable caution. Social arrangements provide the context within which social problems statistics emerge and shape what sorts of numbers gain attention. In my view, any serious effort to make students more numerate about those statistics requires coming to terms with this process of social construction.

\section{Statistics and the Social Construction of Social Problems}

Sociologists who study the social construction of social problems ask how and why particular issues come to public attention: how is it that, at one time or another, toxic breast implants, or road rage, or identity theft come to be seen as important, troubling topics, the focus of considerable public attention. The answer is that people-social activists, experts, media figures, politicians, or whoever-must make claims arguing that something is an important issue, one that requires action. (We can, for instance, see the numeracy movement as constructing innumeracy as an educational problem that needs to be addressed through numeracy education.)

It helps to think about these various claims as competitors in a social problems marketplace (Hilgartner and Bosk 1988). That is, there are advocates promoting many causes, trying to capture the attention of - and arouse concern among - the press, the public, and policymakers. This competition encourages advocates to present the most compelling case possible, in order to grab and hold the audience. Thus, when campaigns illustrate social problems with examples, they choose especially disturbing instances: a child beaten to death may be used to illustrate the problem of child abuse (even though cases of nonviolent neglect far outnumber cases of physical abuse, and even among children who suffer physical abuse, fatalities are rare [Johnson 1995]); and so on.

Similarly, campaigns to arouse concern about social problems often present statistical evidence. Once again, there are competitive advantages to presenting the most compelling numbers. In most cases, this means introducing big numbers. Put simply: a big number suggests there is a big problem. If we can say that a social problem occurs many times each year, or that it affects many people, or that it costs lots of money, we have a stronger case that our problem deserves 
attention - that people ought to worry about it, that they ought to be willing to do something about it.

It is important to appreciate that the advocates seeking to call attention to different social problems are often perfectly sincere: they believe that the problem is important and merits concern. They are also likely to spend time among likeminded individuals, so that a sort of hothouse atmosphere develops around their particular issue. Such people may not be especially critical of numbers that seem to support their claims: they think this is a big problem, so a big number sounds about right.

In addition, of course, advocates often have an interest in their claims' successes. Once people start to take a problem seriously, good things-money, status, and so on - can begin to flow to its promoters. It is quite easy for someone to sincerely believe that some problem demands attention, and for that person to also have a vested interest in that problem gaining attention. Neither characteristic does much to encourage critical thinking about statistics about the problem-at least not regarding those numbers that seem to confirm the problem's importance. (Of course, people often become analytic tigers when confronted with figures that challenge their positions; they start criticizing samples, measurements, etc.)

In order to illustrate these processes, let's examine two avian examplesclaims about bird deaths due to collisions with windows, and about the avian flu.

\section{Dead Birds: Estimates for Deaths from Window Strikes}

When birds fly into windows, the collisions are often fatal. How often does this happen? It is impossible to count every fatal window-strike but, in recent years, the media have reported an impressively large, albeit suspiciously round estimate for the number of fatal bird collisions each year. For instance, an architecture professor interviewed on National Public Radio in 2005 put the annual number of fatal bird strikes at one billion. The reporter conducting the interview expressed skepticism: "How accurate is that number do you think? How would you ever calculate something like that?" The professor offered reassurance, insisting that the one-billion figure was "based on very careful data" ("A Major Risk Factor" 2005).

Tracing the origins of the one-billion statistic proves interesting. The previous best estimate for annual bird deaths due to fatal window collisions in the continental United States was 3.5 million (Banks 1979). This estimate simply assumed that there were about 3.5 million square miles in the continental U.S., 
and that, on average, one bird died after striking a window per square mile. In other words, the 3.5 million figure wasn't much more than a guess.

Convinced that that number was too low, an ornithologist decided to do some research. He arranged to have residents at two houses keep careful track of bird collisions at their homes; one house was in southern Illinois, the other in a suburb in New York. By bizarre coincidence, I happen to have known the people who lived in the Illinois house; they were former neighbors of ours, an older couple who loved birds, and who built a custom home with lots of windows, surrounded by trees, bushes, bird feeders, and so on. Their house was a bird magnet. Over a one-year period, our neighbors observed 33 fatal bird strikes at their home (Klem 1990). (In contrast, we lived for eight years in a house a few hundred yards away; however, most of our windows were screened, and, so far as we knew, no birds died striking our house during those years)

But how do we get to that one-billion estimate? The ornithologist found government estimates for the numbers of housing units, commercial buildings, and schools in the U.S. - a total of 97.6 million structures (Klem 1990). He then estimated that, on average, between one and ten birds would die from flying into each building's windows. Thus, he concluded that between 97.6 million and 975.6 million fatal bird strikes occurred each year. Although some reporters carefully acknowledged the range of estimates (Malakoff 2004), other advocates seized on the larger figure, rounded up and - voila! - concluded that "very careful data" demonstrated that one billion birds die each year from window collisions.

Clearly, some large number of birds dies this way. There is no way to accurately measure this number, and we have to make guesses. If we assume one death per square mile, we get 3.5 million deaths; one death per building gets us about 100 million; ten deaths per building a billion. Certainly a billion is a more arresting figure, and it is the one that has received the most media coverage.

However, not everyone agrees. One bird-death website suggests that only 80 million birds die from window strikes annually (it offers no basis for that figure). However, it states that: "Pet cats that are allowed to roam free account for some 4 MILLION bird deaths EACH DAY in North America, or over 1 BILLION songbirds each year. This figure does not include the losses resulting from feral cats or wild populations of cats" ("Modern Threats to Bird Populations" 2005emphasis in original). Just to put that number in perspective, the federal government estimates that there about 71 million pet cats (including, of course, some who are restricted to an indoor lifestyle) (American Veterinary Medical Association 2002). To kill a billion birds, each of those cats would have to average 14 bird kills annually.

In sum, the estimate that each year a billion birds die in window collisions is a widely disseminated statistic. This example illustrates one of the most common ways statistics are used to discuss social problems: someone gives an estimate for 
the problem's scope. Such big, round-number estimates pop up frequently: someone claims that there are a million cases of elder abuse each year, or two million missing children, or three million homeless persons, or a billion birds killed in window collisions.

I am not sure whether people in the numeracy movement would find such figures particularly interesting. Such numbers do not claim to be the result of complex quantitative reasoning; rather, they are presented as estimates of counts. That is, we are asked to believe that if someone were to simply count the number of cases of the phenomenon in question (e.g., bird deaths from window collisions), the result would be more-or-less the number being claimed. Do such simple numbers offer any useful lessons in numeracy?

In my view, there are at least two important lessons to be learned from examining the billion bird-death figure. The first is that every number is indeed socially constructed, and that we need to understand the process that produced the number. In this case, the ornithologist arrived at the number through a two-stage process. First, he arranged to have the people who lived in the two houses count the number of fatal bird-strikes at their homes. Second, he proposed that 1-10 birds suffered fatal collisions per building, and multiplied an estimate for the total number of buildings by 1 and 10, thereby generating a range for total bird deaths. There is nothing difficult about understanding the calculations that produced the final number, but neither is it difficult imagining that there might be critics who would find the result of this process less than convincing.

The second lesson is that statistics can have a life of their own. That is, once someone has produced a number, others are likely to latch onto the figure and repeat it. When people talk about social issues, they like to have facts to support their arguments and numbers tend to be treated as facts in our culture. Numbers that cannot bear even the most minimal inspection, that may be acknowledged to be nothing more than someone's best guess when they originate, are seized by others because they are the only-and therefore the best-statistics available. Those folks repeat the figure, and with each repetition, there seems to be broader consensus about the number's accuracy. Often, people begin to improve upon the figure.

We see these processes in our bird-death example. The initial estimated range (between 97.6 million and 975.6 million fatal bird strikes annually) was soon forgotten, in favor of the higher figure, which was then rounded up to the more impressive one billion. Thus, "97.6-975.6 million" becomes "as many as one billion," which in turn becomes "a billion." Similarly, expressions of confidence in the figure's accuracy become more robust. What was once a rough estimate becomes "very careful data." Others may even argue that the number understates the problem: thus, an Audubon Society official suggests: "I think [the 
ornithologist who made the original estimate has] been very conservative in his calculations" (Malakoff 2004, 66).

Estimates of a social problem's scope are extremely common. When advocates are trying to draw attention to some issue, they often seek media coverage, and reporters are likely to press for facts - numbers - that can give a sense of just how large the problem is. No matter how carefully the people offering the original figures may be to qualify their claims, there is an excellent chance that those qualifications will soon be lost. This is a very common way for dubious data to enter policy debates.

In my view, advocates of improving numeracy should find such figures worthy of attention, even though they involve rather simple mathematics. Virtually all statistics classes teach students to master a series of increasingly sophisticated concepts and the procedures necessary to conduct the attendant calculations. In general, the more sophisticated the concepts and procedures being taught, the more prestige there is in teaching the material. Choosing to focus on teaching numeracy is risky, in the sense that the skills taught in numeracy education are relatively simple - they don't seem to involve much "real math." And learning to think critically about estimates for the number of birds killed in window collisions (or the numbers of missing children, or homeless people, or whatever) involves minimal mathematical sophistication. These numbers are really just counts (or, rather, estimates of what a more-or-less accurate count would show), and counting seems to be the very simplest mathematical skill. Thinking critically about these numbers directs attention away from more complex, more mathematically interesting forms of reasoning; it requires understanding less about math than about the nature of social construction, the ways that different parties become invested in producing and promoting particular estimates.

My point is not that some numbers are based on poor data analysis. Numeracy requires more than understanding sound analytic practices. To be sure, we might quibble about the ornithologist's methods - the small and apparently unrepresentative sample of houses, the casual guesses about the limits of the range for deaths per building, and so on. But such critiques ignore much larger issues, such as the rhetorical role statistics play in promoting social problems claims, or the way claims must compete for public attention. The example is intended to suggest that numerate thinking about social statistics requires understanding that these numbers are produced and disseminated in a social context, that is, understanding the social construction of those numbers. This becomes even more evident in our second example. 


\section{Deadly Birds: Constructing the Menace of Avian Flu}

During the fall of 2005, and into the early months of 2006, the threat of an epidemic of bird flu became the subject of considerable media attention. There were already doubts about officials' ability to prevent an epidemic. The previous year, contaminated production methods had spoiled a substantial portion of the 2004 flu vaccines, so that many people who ordinarily received flu shots had to go without; then, in August, 2005, Hurricane Katrina raised questions about the competence of those responsible for emergency management. Now, there were warnings that avian flu had broken out in Southeast Asia, and that it might spread into a global pandemic.

Two sorts of numbers in particular helped give this problem shape. The first was the claim that the current strain of flu was extremely virulent, as evidenced by claims that half the known cases had ended in death. If the disease spread widely, and if it killed half the people who contracted it, the consequences would be catastrophic. How catastrophic? Various commentators who speculated on the possible death toll produced an extraordinary range of figures. Thus, The Bird Flu Preparedness Planner warned: “... this is no ordinary flu virus; This new strain is highly lethal, with a death rate of fifty percent, 80 times the normal flu, with the potential to kill hundreds of millions given the right conditions" (Woodson 2005, vii). At the upper end of the range, we find claims that "the true worst-case scenario ... [is] in the range of 1 billion deaths" (Davis 2005, 126; emphasis in original).

Of course, flu epidemics can be serious. The 1918 pandemic that spread in the aftermath of World War I killed millions of people, perhaps 100 million worldwide. But is that the reasonable basis for comparison? After all, the Great War created crowded, unsanitary conditions that made it particularly easy for disease to spread, and standards for medical care have improved significantly over the intervening decades. Wouldn't contemporary society be better able to manage a flu outbreak?

In fact, commentary on the flu risk presented a broad spectrum of views, from doomsday scenarios to dismissive skepticism. Not surprisingly, warnings that the flu posed a dire threat made for more compelling media coverage. These claims sketched a nightmarish sequence of events: what if a particularly deadly strain of bird flu emerged, and what if humans proved susceptible to that particular strain, and what if - once people became infected - the flu organisms mutated so that they could be transmitted directly from one person to another? Skeptics argued that the H5N1 virus had been around for decades without having morphed into a form capable of transmitting lethal infections among large numbers of people, and that this very failure suggested that a deadly pandemic was an unlikely outcome. Still, the prospect of global devastation made for better 
sound bites and more alarming headlines. One list of "practical pre-pandemic preparations for individuals" began: "Get your will in order" (Woodson 2005, 22).

While the worst-case scenarios depended largely upon speculation, numbers did play a role in the alarmed commentary. What about those claims that H5N1 infections had a "death rate of fifty percent"? Commentators noted that half of the people who had been treated had died, and that this demonstrated that the new strain of flu was particularly deadly. But most of these deaths occurred in Vietnam and other Asian countries, and many of those who died had worked with poultry (so they had direct exposure to infected birds). More importantly, the fifty percent death-toll seems to have been calculated using the number of people hospitalized with flu symptoms. In other words, it did not take into account the possibility that some - quite possibly a large majority - of those who became sick with flu stayed home, rather than entering a hospital for treatment. We can suspect that hospitalization is a last resort for low-paid workers in Third World countries, that only the sickest patients would come to official notice. Extrapolating the death rate among the minority of patients who received hospital treatment to the entire population of people who came down with flu created an exaggerated perception of the threat.

Similarly, the wildly varied projections of possible death tolls for a pandemic - figures that ranged from less than one million to one billiondepended upon all manner of assumptions - how far and how widely might the disease spread, how fast might it spread, how effective might medical treatments be for those infected, what might the death rate among the infected be, and so on. Obviously, there were few limits on such speculation. In retrospect, knowing that the actual worldwide death toll was far less than one thousand, the more extravagant claims now seem fantastic - akin to those doomsday predictions for the civilization-ending possibilities of computer software failing to handle the arrival of Y2K. (Some critics noted that this was by no means the first set of warnings to exaggerate the threat of a devastating H5N1 flu pandemic [Fumento 2005].) Attaching numbers - even numbers based on guesses and pessimistic assumptions - to worst-case scenarios seems to make those projections seem more plausible, because figures, even if they are grounded in little more than fantasy, demand to be treated as facts. Somebody must have calculated something, right?

Once again, I am not sure how neatly these statistics - both the 50 percent death rate, and the projections for a death toll of up to a billion people-fit within the domain of numeracy education. To be sure, it is easy to criticize the basis for those numbers - the failure to appreciate that the number of people sick enough to be hospitalized is not the best basis for calculating death rates, the readiness to string together a series of extremely pessimistic assumptions to arrive at a worst- 
case guess for how high the final death toll might be. But understanding warnings about the flu epidemic really requires understanding how claims regarding different social problems compete for media attention, and how coverage depends upon constructing an issue in compelling terms - which often means in the most frightening terms - that will allow it to elbow aside rival concerns.

\section{Critical Thinking about Numeracy Cannot Be Divorced from Social Context}

Any number can be understood as the result of some set of calculations - or more sophisticated quantitative procedures - that produced it. Because many numeracy advocates seem to either be mathematicians, or to teach statistics or research methods in other disciplines, there may be a natural tendency to think of numeracy in those terms. That is, they may focus on the quantitative reasoning and methodological choices used to produce numbers, rather than the broader social context within which that reasoning occurs.

But, when we try to think critically about many of the numbers we encounter in discussions of social or political issues, coming to terms with the actual quantitative methods used to produce those figures is only part-and often a relatively uninteresting part-of the story. How did advocates arrive at the claim that a billion birds die in window collisions, or that bird flu might kill a billion people worldwide? These were little more than guesses, ballpark figures. In the 1980s, when a leading activist was asked to explain the basis for the widely circulated estimate that there were three million homeless Americans, he responded: "Everybody demanded it. Everybody said we want a number. . . . We got on the phone, we made a lot of calls, we talked to a lot of people, and we said, 'Okay, here are some numbers.' They have no meaning, no value" (Mitch Snyder quoted in Jencks 1994, 2). Not surprisingly, such casually produced estimates can prove to be off by one or more (in the case of the worst-case scenarios for avian flu, several) orders of magnitude. Still, the mathematical, quantitative-reasoning lesson illustrated by such examples is pretty basic: guessing is often inaccurate.

To fully understand the sorts of numbers that tend to appear in media reports, we need go beyond examining calculations, to explore the social processes that produce those figures, the ways people go about socially constructing statistics. Here, I should emphasize, I am referring, not just to activists' estimates for the scope of social problems, but also to press coverage of government agency announcements, research results, and other seemingly authoritative figures (e.g., shifts in the crime rate, evidence of some health hazard reported in a medical journal, rankings of colleges, and so on). Within sociology, economics, and 
political science, for instance, there are whole literatures discussing the problems with how the federal government measures the population, crime, poverty, unemployment, productivity, and on and on. Even the most familiar social statistics are products of choices that can be questioned. Moreover, one needs to think critically about social construction at two different levels.

The first of these levels concerns the social processes-the decisions and procedures that lead to the production of the specific numbers in question. Thus, we can unpack the billion bird-deaths figure to identify the ornithologist who produced it, the calculations he used to estimate a range of bird deaths, and the ways other people improved the number (by focusing on the upper range, rounding up, and characterizing the statistic as the product of careful research). It is possible to discover analogous information for any figure. Sometimes, such information is readily available: If we read a news story reporting on a recent piece of medical research, we should be able to locate the journal where the article appeared and discover the information in the methods section. In other cases, of course, determining how people arrived at a number may require more detective work. But we can at least try to discover the process by which numbers are produced.

The second level seems further from the traditional concerns of numeracy's advocates, but it strikes me as nonetheless important. This involves teaching students to understand the larger social context within which numbers emerge. Causes compete for our attention and concern, and statistics play an important rhetorical role in social problems construction. This has various consequences, including creating a marketplace where the most compelling claims win, and less persuasive arguments get pushed aside. Thus, advocates prefer dramatic statistics, and this preference usually translates into big numbers. Big numbers make claims more attractive to the various media that showcase claims - not just newspapers or TV news shows but presumably more selective venues, such as medical journals that use press releases to maintain a public profile (Shell 1998). It is no accident that the claims about both dead and deadly birds fixed on the same figure-one billion. A billion is a big, round, impressive number. If a billion birds die flying into windows, or if bird flu might kill a billion people, we can recognize that we're talking about big, troubling problems. The persuasive appeal of such alarming statistics is to give those claims that incorporate them a competitive advantage in the social problems marketplace, no matter how dubious the assumptions that underpin the calculations that led to those figures. Trying to deal one-by-one with examples of bad numbers risks overlooking the larger social context that shapes the choices made by the people who produce and repeat the dubious figures that appear in nearly every newscast or newspaper. 


\section{Implications for Teaching Numeracy: A Non-Avian Example}

What does this mean for those directly engaged in numeracy education? Because I don't teach courses in quantitative literacy, I am ill-qualified to suggest how instruction might be improved. But let me offer a non-avian example of the sort of topic I think might warrant classroom attention. The U.S. Census Bureau (2007) recently announced that: "The non-Hispanic, single-race white population [is] 66 percent of the total population." News reports interpreted this as a milestone: for the first time in U.S. history, over a third of Americans were minority group members.

Racial and ethnic classifications are always messy, as the press release's awkward phrasing suggests. What does it mean to say that someone is a "nonHispanic, single-race white"? First, the federal government does not consider "Hispanic" a race; Hispanics are of different races, including many who consider themselves white. Second, thanks to recent changes in census questions, respondents are now invited to declare themselves to be of more than one race. In particular, Native American activists have urged individuals with some American Indian ancestry to acknowledge this. In its press release, the bureau classified all Hispanics and anyone who acknowledged any non-white ancestry as minority group members; that is, they classified people so as to maximize the non-white population. Very likely, a good many of the people counted as minority group members for this purpose consider themselves - and are considered by others - to be white in everyday life. As recently as the 1990 census, the bureau used a different scheme in which many of these individuals would have been classified as part of the white population.

Still, we can understand the broad appeal of the statistical milestone produced through the new classification scheme. It seemed newsworthy-minorities now account for more than a third of the population. It also advanced the political interests of activists on both the left (who could call for greater appreciation of diversity, and so on) and on the right (who could, for instance, point with alarm to the impact of immigration). There were reasons why this particular news release attracted considerable attention, but fully understanding this requires understanding both how government agencies classify race (what strikes me as a more traditional topic for numeracy education), and the political interests various groups have in those classifications (which would require thinking more about the process of social construction). In my view, teaching students about such examples requires addressing both topics. 


\section{The Bottom Line}

I have tried to argue that social construction poses a challenge for those interested in promoting numeracy. Once we acknowledge that all numbers are products of social activity, we must confront the nature of the social environment in which numbers emerge and circulate. And that means moving numeracy education beyond the confines of teaching calculation and statistical concepts, to address matters of social construction.

Acknowledgment: Several reviewers offered helpful suggestions for improving this paper.

\section{References}

American Veterinary Medical Association. 2002. U.S. Pet Ownership \& Demographics Sourcebook. Schaumburg, IL: AVMA.

Banks, R. C. 1979. "Human related mortality of birds in the United States." U.S. Fish and Wildlife Service Special Scientific Report, Wildlife No. 215.

Berger, P. L., and T. Luckmann. 1966. The Social Construction of Reality: A Treatise in the Sociology of Knowledge. Garden City, NY: Doubleday.

Best, J. 2001. Damned Lies and Statistics: Untangling Numbers from the Media,Politicians, and Activists. Berkeley: University of California Press.

- 2004. More Damned Lies and Statistics: How Numbers Confuse Public Issues. Berkeley: University of California Press.

- 2008. Historical development and defining issues of constructionist inquiry. In Handbook of Constructionist Research, ed. J. A. Holstein and J. F. Gubrium, 41-64. New York: Guilford.

Boghossian, P. 2006. Fear of Knowledge: Against Relativism and Constructivism. Oxford: Clarendon Press.

Davis, M. 2005. The Monster at Our Door: The Global Threat of Avian Flu. New York: New Press.

Fumento, M. 2005. Fuss and feathers: Pandemic panic over the avian flu. Weekly Standard 11 (November 21)

Hilgartner, S., and C. L. Bosk. 1988. The rise and fall of social problems. American Journal of Sociology 94: 53-78. http://dx.doi.org/10.1086/228951

Huff, D. 1954. How to Lie with Statistics. New York: Norton. Jencks, C. 1994. The Homeless. Cambridge, MA: Harvard University Press. 
Johnson, J. M. 1995. Horror stories and the construction of child abuse. In Images of Issues, $2^{\text {nd }}$ ed., ed. J. Best, 17-31. Hawthorne, NY: Aldine de Gruyter.

Klem, D., Jr. 1990. Collisions between birds and windows: Mortality and prevention. Journal of Field Ornithology 61: 120-128.

"A Major Risk Factor for Birds: Building Collisions." 2005. All Things Considered (March 11). http://www.npr.org

Malakoff, D. 2004. Clear and Present Danger. Audubon Magazine 106 (March): 65-68.

"Modern Threats to Bird Populations." 2005. Chipper Woods Bird Observatory. http://www.wbu.com/chipperwoods/photos/threats.htm

Shell, E. R. 1998. The Hippocratic wars. New York Times Magazine (June 28): 34-38.

U. S. Census Bureau. 2007. Minority population tops 100 million, news release, May 17. http://www.census.gov/newsroom/releases/archives/population lcb07-70.html

Woodson, Grattan. 2005. The Bird Flu Preparedness Planner. Deerfield Beach, FL: Health Communications. 